\title{
Combined use of LIDAR and hyperspectral measurements for remote sensing of fluorescence and vertical profile of canopies
}

\author{
Ounis, A. ', Bach, J. ${ }^{* 1}$, Mahjoub, A. ${ }^{2}$, Daumard, F. ${ }^{3}$, Moya, I. ${ }^{1}$, Goulas, Y. ${ }^{1}$ \\ ' Laboratoire de Météorologie Dynamique, École Polytechnique, F91128 Palaiseau, France. \\ ${ }^{2}$ Laboratoire de Physique des Plasmas, École Polytechnique, F91128 Palaiseau, France. \\ ${ }^{3}$ INRA-EGC, Thiverval-Grignon, France.
}

\begin{abstract}
We report the development of a new LIDAR system (LASVEG) for airborne remote sensing of chlorophyll fluorescence (ChIF) and vertical profile of canopies. By combining laser-induced fluorescence (LIF), sun-induced fluorescence (SIF) and canopy height distribution, the new instrument will allow the simultaneous assessment of gross primary production (GPP), photosynthesis efficiency and above ground carbon stocks. Technical issues of the fluorescence LIDAR development are discussed and expected performances are presented.
\end{abstract}

Key words: laser-induced fluorescence, sun-induced fluorescence, LIDAR, chlorophyll fluorescence, fluorescence yield, vegetation stress, canopy profile, LIDAR waveform, gross primary production.

\section{Uso combinado del LIDAR y medidas hiperspectrales para la teledetección de la fluorescencia y el perfil vertical del dosel}

Resumen: Se presenta el desarrollo de un nuevo sistema LIDAR (LASVEG) para la teledetección aerotransportada de la fluorescencia de la clorofila (ChlF) y el perfil vertical del dosel. Mediante la combinación de la fluorescencia inducida por láser (LIF), la fluorescencia inducida por el sol (SIF) y la distribución de la altura del dosel, el nuevo instrumento permitirá la evaluación simultánea de la producción primaria bruta (GPP), la eficiencia de la fotosíntesis y las reservas de carbono por encima del nivel del suelo. Se discuten cuestiones técnicas del desarrollo del LIDAR fluorescencia y se presentan las prestaciones previstas.

Palabras clave: fluorescencia inducida por láser, fluorescencia inducida por el Sol, LIDAR, fluorescencia de la clorofila, rendimiento de la fluorescencia, estrés de la vegetación, perfil del dosel, forma de onda LIDAR, producción primaria bruta.

\section{Introduction}

Terrestrial vegetation plays a fundamental role in the global carbon cycle. However, the coupling between climate change and plant eco-physiological functions still remains poorly understood. Experimental investigations at the leaf, canopy, ecosystem and regional scales are needed in order to improve climate predictions and mitigation strategies. 
In this framework, remote sensing of sunlight reflected by the earth surface in the visible and near infrared (VIS-NIR) has long been a common technique to assess vegetation state (Glenn et al., 2008). Vegetation indices derived from VIS-NIR spectrum, or regression algorithms that exploit the full spectrum were developed to infer main vegetation biophysical parameters such as Leaf Area Index (LAI) (Haboudane et al., 2004), leaf chlorophyll content (Chl) (Dash \& Curran, 2007) or the fraction of absorbed photosynthetically active radiation (fraction of APAR or fAPAR) (Baret et al., 2007). At the ecosystem scale, waveform LIDARs have been introduced to analyze canopy height and structure as a proxy for trees biomass stocks (Asner et al., 2012; Mascaro et al., 2011). However, these techniques only deliver information on biophysical variables of the canopy, not on eco-physiological functions.

Chlorophyll fluorescence (ChlF) is emitted by the photosynthetic pigments pool shortly after light absorption. It is considered as a promising remote observable of vegetation because of its close link with photosynthesis. ChlF has been used for decades to assess photosynthesis at leaf scale in the laboratory and on the field (for a review see Papageorgiou \& Govindjee, 2004). Recently, a strong correlation was evidenced between sun-induced fluorescence (SIF) measured from space and gross primary production (GPP) of various biomes derived from eddy covariance measurements at ground level (Frankenberg et al., 2011; Guanter et al., 2014). However, GPP depends on both: (i) APAR, which itself depends on canopy structure, leaf biochemical composition and on incident radiation level, and (ii) the light use efficiency (LUE), which reflects the eco-physiological state of the plant (Monteith, 1972). On the other hand, SIF depends also on APAR and on the fluorescence quantum yield (FQY), which is linked to photosynthesis efficiency.

FQY is defined as the ratio of the total emitted fluorescence to the amount of light absorbed by photosynthetic pigments. The principle underlying the relationship between FQY and photosynthesis is relatively straightforward. Light energy absorbed by chlorophyll molecules can undergo three different fates: it can be used to drive photosynthesis (by photochemistry), it can be dissipated as heat or it can be re-emitted as fluorescence. These three processes are in competition, and any increase in the efficiency of one will result in a decrease in the yield of the other two. Hence, disentangling APAR effects from LUE effects in GPP is possible if we are able to measure FQY independently. Absolute values of FQY are difficult to obtain experimentally (Cerovic et al., 1996). However, relative changes in FQY can be measured on leaf at short time scales by active fluorometers. In this case, experimental conditions such as measuring distance, source intensity, chlorophyll content, etc, are kept constant. By using pulsed modulated excitation, relative changes in FQY can be assess in the presence of background illumination, even in full sun light (Schreiber et al., 1988; Schreiber \& Schliwa, 1987). Analysis of FQY changes with light and other environmental conditions founds the basis of the use of ChlF for assessment of photosynthesis in plant physiology, ecophysiology and agronomy (Krause \& Weis, 1991; Maxwell \& Johnson, 2000; Papageorgiou \& Govindjee, 2004).

Assessment of relative FQY changes is still feasible at canopy level with active sensors if all measuring conditions are kept constant. In such cases, the fluorescence signal at sensor level (F) remains proportional to FQY, thus giving access to physiological changes from remote. In a study on water stress in vineyard, Lopez et al. (2011) show that $F$ undergoes a significant decrease $(10-15 \%)$ at noon upon stress. This shows that remote sensing of plant stress by ChlF is achievable if we are able to characterize changes in FQY at canopy level.

In this paper, we propose a new instrumental concept that combines laser induced fluorescence (LIF) and SIF measurements on a single platform. This development takes place in the framework of a multi-partners program supported by the French space agency CNES and the French national agency ANR: the CALSIF project (CAnopy Laser and Sun Induced Fluorescence). We describe this new instrumental concept and we discuss developmental issues and new possibilities that are open up by this new airborne instrument.

\section{Measuring principles}

CALSIF project aims to fill the gap between eddy fluxes towers and space observation: 
- SIF gives access to GPP, a major component of carbon fluxes between surface and atmosphere (Frankenberg et al., 2011; Rossini et al., 2010).

- LIF, as a proxy of FQY, allows assessment of fluorescence quenching, thus giving access to photosynthetic efficiency (Flexas et al., 2002).

- LIDAR waveform maps above ground carbon stocks through the use of allometric relationships (Asner, et al. 2012).

SIF and GPP share APAR as a common factor (Rossini et al., 2010; Damm et al., 2010). GPP is expressed as:

$G P P=A P A R \times L U E$

where LUE, as seen above, represents the fraction of absorbed PAR that is used for carbon fixation. On the other hand, SIF can be written as:

$S I F=A P A R \times F Q Y \times \tau_{F}$

where $\tau_{F}$ is the fraction of emitted fluorescence that escapes from the canopy. FQY can be assessed from LIF existence considering Eq. 3:

$L I F=I_{\text {laser }} \times f A P A R_{\text {laser }} \times F Q Y \times \tau_{\text {Flaser }}$

$I_{\text {laser }}$ being the laser intensity, $f A P A R_{\text {laser }}$ the fraction of laser light absorbed by vegetation and $\tau_{\text {Flaser }}$ the fraction of laser induced fluorescence that escapes from the canopy. In the case of LIF, the illumination geometry is constant between measurements made at the same place at different times during the day. Hence, $I_{\text {laser }}, f A P A R_{\text {laser }}$ and $\tau_{\text {Flaser }}$ are constant and LIF can be regarded as a proxy for time variations of FQY. In the far-red (see Figure 1), $\tau_{F}$

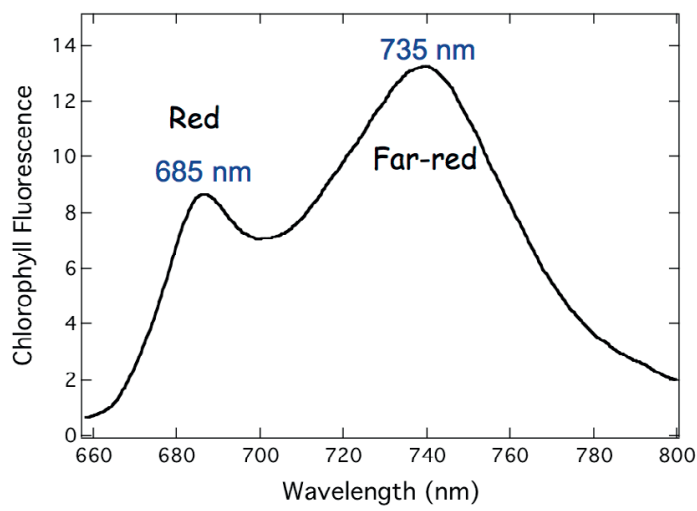

Figure 1. Chlorophyll fluorescence spectrum. is close to one as fluorescence is not reabsorbed at these wavelengths. Hence, combining Equations 1 to 3 gives the possibility to investigate the relationship between LUE and FQY and to improve GPP modeling using fluorescence.

Airborne LIDARs have been shown to be able to map above ground carbon stocks in tropical forests by measuring trees height and using allometric relationships (Asner et al., 2012; Mascaro et al., 2011). The CALSIF LIDAR will have the capability to record the full waveform of the backscattered light in the excitation wavelength channel $(532 \mathrm{~nm})$ at a vertical resolution of 3.5 meters. This resolution is achieved due to the high sampling rate (250 Msamples/s) and the short duration of the laser pulse (7 ns).

Canopy reflectance will also be acquired to derive vegetation indices [e.g. NDVI, Normalized Difference Vegetation Index; PRI, Photochemical Reflectance Index, (Gamon et al., 1992)]. For critical review on vegetation indices see Glenn et al., 2008.

To perform these measurements, the CALSIF instrument will integrate the following sub-instruments:

1.A fluorescence LIDAR (LASVEG), with a single excitation wavelength at $532 \mathrm{~nm}$ and three detection channels at 532, 685 and $740 \mathrm{~nm}$. This LIDAR will also perform range detection for canopy height determination.

2. A passive fluorosensor based on a modified version of the AIRFLEX sensor already developed for passive remote sensing of SIF (Moya et al., 2006).

3. A wide band spectrometer to detect vegetation reflectance spectrum between $400 \mathrm{~nm}$ and $1000 \mathrm{~nm}$.

4. A time synchronized video camera to record images of the scene that will help target identification.

The CALSIF instruments operate in nadir viewing at a $20 \mathrm{~Hz}$ sampling rate to acquire data along a profile line of $5 \mathrm{~m}$ thickness. At a typical aircraft speed of $80 \mathrm{~m} / \mathrm{s}$, sampling distance is $4 \mathrm{~m}$, according an overlap between measurements. Fields of view of the CALSIF instruments are matched to each other so that the footprints are the same 
for active and passive instruments (about $8 \mathrm{mrad}$ half-angle, which represents a footprint of 5 meters at an altitude of 300 meters). Interferences between the LIDAR and the passive instruments (i.e. AIRFLEX and the spectrometer) can be avoided using different strategies that will be implemented and tested: (i) measurements are synchronized against a common master clock so that passive acquisitions only take place when the laser does not shot, (ii) passive measurements are referenced against the laser clock and postprocessed to keep only the non-interfering ones, (iii) the line of sight of the passive instruments is deviated by $1^{\circ}$ along track (forward or backward).

\section{The fluorescence LIDAR}

The goal of the fluorescence LIDAR is to measure laser-induced fluorescence from an airborne platform at a moderate altitude $(300-500 \mathrm{~m})$ in both red and far red bands of chlorophyll fluorescence. It uses a compact and rugged lamp-pumped and frequency doubled Nd:YAG laser pulsed at a frequency of $20 \mathrm{~Hz}$ with $30 \mathrm{~mJ}$ energy per pulse (Ultra 50, Quantel, Les Ulis, France) as the excitation source.

\subsection{Signal to noise ratio}

Because of the low fluorescence yield $(<1 \%)$ of in vivo chlorophyll, the instrumental design needed to perform high-quality data becomes challenging. Therefore, we setup a ground test to investigate the overall detectability of the LIF. Using laser pulses

Table 1. Fluorescence LIDAR specifications.

\begin{tabular}{ll}
\hline Laser & \\
Excitation wavelength & $532 \mathrm{~nm}$ \\
Pulse energy & $30 \mathrm{~mJ}$ \\
Pulse duration & $6-7 \mathrm{~ns}$ \\
Pulses frequency & $20 \mathrm{~Hz}$ \\
Beam divergence (half angle) & $8 \mathrm{mrad}$ \\
Spot diameter at $300 \mathrm{~m}$ & $5 \mathrm{~m}$ \\
Detection & \\
Telescope with Fresnel lens & \\
Diameter: & $0.35 \mathrm{~m}$ \\
Focal length: & $0.4 \mathrm{~m}$ \\
Detector size & $10 \times 10 \mathrm{~mm}^{2}$ \\
Operating range & $300 \mathrm{~m}$ \\
Acquisition & \\
Sample rate & $250 \mathrm{MS} / \mathrm{s}$ \\
\hline
\end{tabular}

of $9 \mathrm{~mJ} /$ pulse at $532 \mathrm{~nm}$ on a tree canopy situated at a distance of $42 \mathrm{~m}$, we achieved fluorescence measurements with $\mathrm{SNR}=100$. By increasing the laser pulse energy up to $30 \mathrm{~mJ}$, and the telescope diameter from $15 \mathrm{~cm}$ to $35 \mathrm{~cm}$, and by improving the detector response time $(+50 \%)$ and the stray light rejection $(+50 \%)$, a SNR of 100 at a flying altitude of $300 \mathrm{~m}$ should be achieved.

\subsection{The excitation source}

Figure 2 shows a schematic drawing of the excitation source. The laser beam is expanded with a negative lens so that the illuminated area is around 5-m diameter for a typical operational flight-altitude of $300 \mathrm{~m}$. Such a beam size is required to operate in eye-safety conditions on the ground level. Energy pulses are recorded with a pyro-electric joule-meter (ED 200, Gentec, Québec, Canada) in order to obtain normalized fluorescence and reflectance ratios. To record the energy of each pulse and trigger the data acquisition system we use the first order beams transmitted by a diffraction grating: at $532 \mathrm{~nm}$, these beams have a sampling ratio of $1.06 \%$ at an angle of $10^{\circ}$. A photo-detector is used to detect the presence of laser pulses.

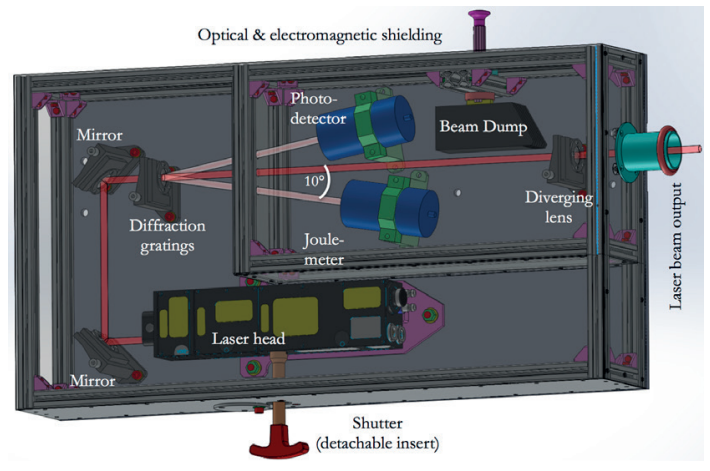

Figure 2. 3D view of the excitation source.

\subsection{Eye safety experimental condition}

To avoid eye injury during operation, the energy received on ground must be far under the Maximum Permissible Exposure. MPEs are defined by the international standard IEC 60825, and depend on wavelength, pulses frequency and exposure time. This later parameter depends on spot 
size at ground level and aircraft speed. Figure 3 gives MPE as a function of illuminated spot diameter at ground level, compared to the exposure $\left(1.5 \mathrm{~mJ} \mathrm{~m}^{-2}\right)$ induced by the LASVEG source at $300 \mathrm{~m}$. It shows that eye safety is achievable under good operational conditions.

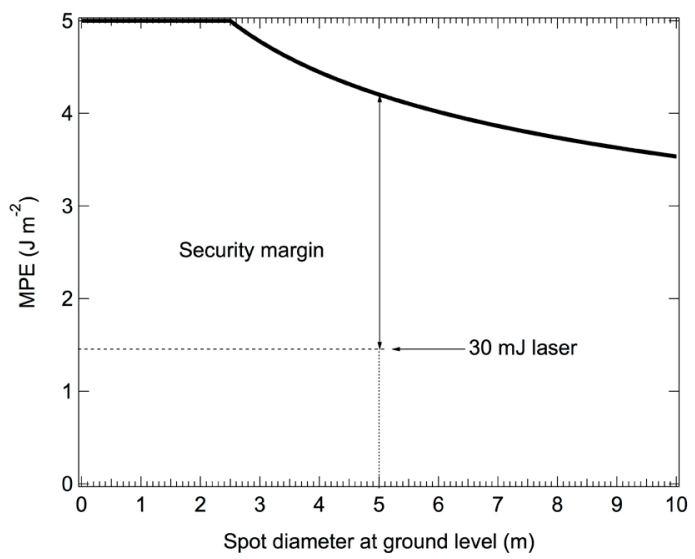

Figure 3. Maximum Permissible Exposure as a function of illuminated spot size at ground level with aircraft speed of $50 \mathrm{~m} \mathrm{~s}^{-1}$.

\subsection{The telescope}

Photon collection is performed with a Fresnel lens of a clear-aperture of $35 \mathrm{~cm}$ (Figure 4). Fresnel lenses have several benefits such as large aperture,

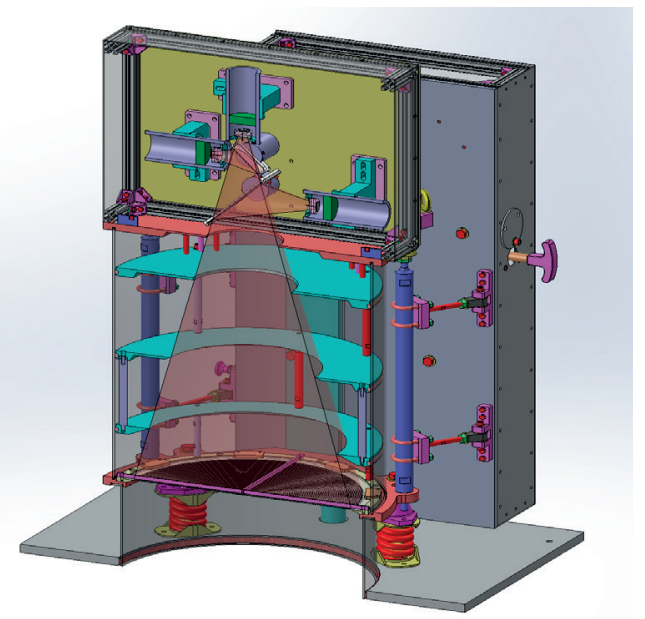

Figure 4. Cross-section view of the LIDAR telescope. large numerical aperture, reduced weight and low cost. In the other hand, commercial available telescopes are not suited for this kind of detection due to their typical numerical aperture. A set of 4 baffles is used to minimize stray-light. Fluorescence and back reflected-light are split into three channels by two dichroic mirrors: one channel at $532 \mathrm{~nm}$ for waveform analysis and two fluorescence channels at $685 \mathrm{~nm}$ and $740 \mathrm{~nm}$ (see Figures 4 and 5). The whole LIDAR system is mounted above the aircraft aperture through silent blocks.

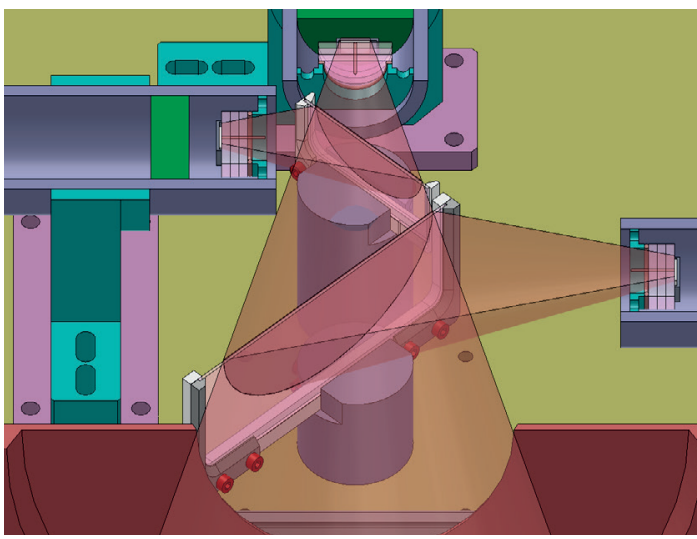

Figure 5. Schematic drawing of the LASVEG detector chamber with dichroïc mirrors.

\subsection{Lidar detectors}

Three high-speed p-type intrinsic n-type semiconductor (PIN) photodiodes are used for fluorescence and waveform detection. At $300 \mathrm{~m}$ operating distance, and considering eye-safe operation (see $\S 3.3$ ), LIF radiance at top of canopy (TOC) is higher than daylight background at both fluorescence peaks, even for a surface of albedo 1 (Figure 6). Airborne measurements and MODTRAN 4 simulations have shown that the contributions of the atmosphere and the environment remain moderate (i.e. $<15 \%$ ) at an altitude of $300 \mathrm{~m}$, and will not change the ratio between LIF and the reflected daylight given by Figure 6 (Daumard et al. 2015). In any case, daylight background is far from being negligible and should be rejected for accurate measurements. Reflected day light has low frequency variations $(<10 \mathrm{~Hz})$ caused by aircraft movement and scene configuration, and 
can be separated from LIF which has much higher frequency components ( $1 \mathrm{kHz}$ and over). For this purpose, we developed a specific trans-impedance amplifier that can reject daylight signal with high efficiency $(50 \mathrm{~dB})$.

The three signals are sampled at high rate (250 MSample/s) with a fast analog to digital card (NI 5761 digitizer coupled to a NI-7961R FPGA Module, National Instruments, Austin, TX, USA) and recorded on a hard disk (250 GB) for post processing. Peak values of fluorescence channels are divided by the pulse energy to give apparent fluorescence yield. The vertical structure of the canopy is deduced from waveform analysis of the reflected laser beam.

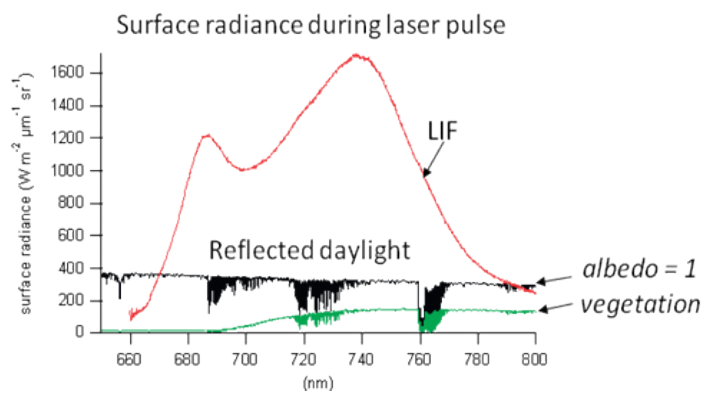

Figure 6. Comparison between laser-induced fluorescence (LIF, red curve) and surface radiances under daylight illumination (surface of albedo 1, black; vegetation, green) obtained from simulations. LIF and canopy reflectance are simulated with the FSAIL model (Miller et al., 2005) with $\mathrm{LAI}=6$ and leaf chlorophyll content $=24 \mu \mathrm{g} \mathrm{cm}^{-2}$. Solar irradiance is simulated with MODTRAN 4 (Berk et al., 1987) upon clear sky conditions at noon.

\section{Passive instruments}

The SIF sensor is based on an improved version of the AIRFLEX sensor, previously used in airborne campaigns (Moya, et al., 2006). AIRFLEX is a six-channels high performance radiometer dedicated to retrieval of far red SIF in the $\mathrm{O}_{2}$-A band, PRI and NDVI (see Table 2 for a description of the channels). Passive instruments include also a wide-band spectrometer (from Ocean Optics) to record the full canopy reflectance spectrum between $400 \mathrm{~nm}$ and $1000 \mathrm{~nm}$. A synchronized video camera is used to record images of the scene that will help for target identification.
Table 2. Characteristics of the AIRFLEX hyperspectral sensor for passive fluorescence measurements. The six radiometric channels of the sensor are used for retrieval of far red fluorescence in the $\mathrm{O}_{2}-\mathrm{A}$ band, photochemical reflectance index (PRI), and normalized difference vegetation index (NDVI). The off-band $\mathrm{O}_{2}-\mathrm{A}$ channel at $770 \mathrm{~nm}$ is also used for NDVI.

\begin{tabular}{lcc}
\hline Band & $\begin{array}{c}\text { Central wave- } \\
\text { length (nm) }\end{array}$ & $\begin{array}{c}\text { Full Width at } \\
\text { Haximum } \\
(\mathrm{nm})\end{array}$ \\
\hline Fluorescence retrieval & & \\
$\mathrm{O}_{2}$-A, Off band & 758.10 & 1 \\
$\mathrm{O}_{2}$-A, In-band & 760.45 & 1 \\
$\mathrm{O}_{2}$-A, Off-band & 770.0 & 1 \\
Photochemical Reflectance Index & 5 \\
Signal & 531 & 5 \\
Reference & 570 & \\
Normalized Difference Vegetation Index & 660 & 3 \\
\multicolumn{2}{l}{ Chlorophyll absorption } & 660
\end{tabular}

\section{Conclusions and perspectives}

We presented a new instrumental concept that combines measurements of LIF, SIF and vertical profile of canopies. This multi-parameter instrument can simultaneously provide photosynthetic efficiency, gross instantaneous carbon flux and above ground carbon stock, which are major eco-physiological variables of canopy functioning. It is expected to resolve major issues in the improvement of GPP models based on fluorescence, with benefits for fluorescence space missions like GOSAT, OCO-2 or FLEX. The first operational tests of the CALSIF instrument are scheduled for the beginning of 2017. The instrument will be operated by the Laboratoire de Météorologie Dynamique, Palaiseau, France and will be available to researchers in areas such as vegetation productivity, carbon cycle or impact of climate changes on ecosystems.

\section{Acknowledgments}

This instrument is developed in the framework of the CALSIF project with the support of the French national agency ANR and the French space agency CNES. 


\section{References}

Asner, G.P., Mascaro, J., Muller-Landau, H.C., Vieilledent, G., Vaudry, R., Rasamoelina, M., Hall, J.S., van Breugel, M. 2012. A universal airborne LiDAR approach for tropical forest carbon mapping. Oecologia, 168(4), 1147-1160. http://dx.doi. org/10.1007/s00442-011-2165-z

Baret, F., Hagolle, O., Geiger, B., Bicheron, P., Miras, B., Huc, M., Berthelot, B., Niño, F., Weiss, M., Samain, O., Roujean, J.L., Leroy, M. 2007. LAI, fAPAR and fCover CYCLOPES global products derived from VEGETATION - Part 1: Principles of the algorithm. Remote Sensing of Environment, 110(3), 275-286. http://dx.doi.org/10.1016/j.rse.2007.02.018

Berk, A., Bernstein, L.S., Robertson, D.C. 1987. MODTRAN: A moderate resolution model for LOWTRAN, Burlington, MA, USA: Spectral Sci., Inc.

Cerovic, Z.G., Goulas, Y., Gorbunov, M., Briantais, J.M., Camenen, L., Moya, I. 1996. Fluorosensing of water stress in plants. Diurnal changes of the mean lifetime and yield of chlorophyll fluorescence, measured simultaneously and at distance with a t-LIDAR and a modified PAM-fluorimeter, in maize, sugar beet and Kalanchoë. Remote Sensing of Environment, 58(3), 311-321. http://dx.doi. org/10.1016/S0034-4257(96)00076-4

Damm, A., Elbers, J., Erler, A., Gioli, B., Hamdi, K., Hutjes, R., Kosvancova, M., Meroni, M., Miglietta F., Moersch, A., Moreno, J., Schickling, A., Sonnenschein, R., Udelhoven, T., Van Der Linden, S., Hostert, P., Rascher, U. 2010. Remote sensing of sun-induced fluorescence to improve modeling of diurnal courses of gross primary production (GPP). Global Change Biology, 16(1), 171-186. http:// dx.doi.org/10.1111/j.1365-2486.2009.01908.x

Dash, J., Curran, P.J. 2007. Evaluation of the MERIS terrestrial chlorophyll index (MTCI). Advances in Space Research, 39(1), 100-104. http://dx.doi. org/10.1016/j.asr.2006.02.034

Daumard, F., Goulas, Y., Ounis, A., Pedros, R., Moya, I. 2015. Measurement and Correction of Atmospheric Effects at Different Altitudes for Remote Sensing of Sun-Induced Fluorescence in Oxygen Absorption Bands. IEEE Transactions on Geoscience and Remote Sensing, 53(9), 5180-5196. http://dx.doi. org/10.1109/TGRS.2015.2418992

Flexas, J., Escalona, J.M., Evain, S., Gulias, J., Moya, I., Osmond, C.B., Medrano, H. 2002. Steady-state chlorophyll fluorescence (Fs) measurements as a tool to follow variations of net $\mathrm{CO}_{2}$ assimilation and stomatal conductance during water-stress in $\mathrm{C}_{3}$ plants. Physiologia Plantarum, 114(2), 231-240. http:// dx.doi.org/10.1034/j.1399-3054.2002.1140209.x
Frankenberg, C., Fisher, J. B., Worden, J., Badgley, G., Saatchi, S.S., Lee, J.E., Toon, G.C., Butz, A., Jung, M., Kuze, A., Yokota, T. 2011. New global observations of the terrestrial carbon cycle from GOSAT: Patterns of plant fluorescence with gross primary productivity. Geophysical Research Letters, 38(17), L17706. http://dx.doi. org/10.1029/2011GL048738

Gamon, J.A., Penuelas, J., Field, C.B. 1992. A narrowwaveband spectral index that tracks diurnal changes in photosynthetic efficiency. Remote Sensing of Environment, 41(1), 35-44. http://dx.doi. org/10.1016/0034-4257(92)90059-S

Glenn, E.P., Huete, A.R., Nagler, P.L., Nelson, S.G. 2008. Relationship between remotely-sensed vegetation indices, canopy attributes and plant physiological processes: what vegetation indices can and cannot tell us about the landscape. Sensors, 8, 2136-2160. http://dx.doi.org/10.3390/s8042136

Guanter, L., Zhang, Y., Jung, M., Joiner, J., Voigt, M., Berry, J.A., Frankenberg, C., Huete, A.R., ZarcoTejada, P., Lee, J.E., Moran, M.S., Ponce-Campos, G., Beer, C., Camps-Valls, G., Buchmann, N., Gianelle, D., Klumpp, K., Cescatti, A., Baker, J.M., Griffis, T.J. 2014. Global and time-resolved monitoring of crop photosynthesis with chlorophyll fluorescence. Proceedings of the National Academy of Sciences, 111(14), E1327-E1333. http://dx.doi. org/10.1073/pnas.1320008111

Haboudane, D., Miller, J.R., Pattey, E., Zarco-Tejada, P.J., Strachan, I.B., 2004. Hyperspectral vegetation indices and novel algorithms for predicting green LAI of crop canopies: Modeling and validation in the context of precision agriculture. Remote Sensing of Environment, 90(3), 337-352. http://dx.doi. org/10.1016/j.rse.2003.12.013

Krause, G.H., Weis, E. 1991. Chlorophyll fluorescence and photosynthesis: The basics. Annual Review of Plant Physiology and Plant Molecular Biology, 42, 313-349. http://dx.doi.org/10.1146/annurev. pp.42.060191.001525

Lopez, M.L., Moya, I., Balbontin, C., Campos, I., Calera, A., Ounis, A., et al. 2011. In-the-field water stress detection at plant scale using Laser Induced Fluorescence. Paper presented at the European Geosciences Union General Assembly, Vienna, Austria. 03-08 April 2011.

Mascaro, J., Detto, M., Asner, G.P., Muller-Landau, H.C. 2011. Evaluating uncertainty in mapping forest carbon with airborne LiDAR. Remote Sensing of Environment, 115(12), 3770-3774. http://dx.doi. org/10.1016/j.rse.2011.07.019 
Maxwell, K., Johnson, G.N. 2000. Chlorophyll fluorescence - a practical guide. Journal of Experimental Botany, 51(345), 659-668. http:// dx.doi.org/10.1093/jexbot/51.345.659

Miller, J., Berger, M., Goulas, Y., Jacquemoud, S., Louis, J., Mohammed, G., et al. 2005. Development of a Vegetation Fluorescence Canopy Model - Final Report: ESTEC Contract N0 16365/02/NL/FF.

Monteith, J.L. 1972. Solar radiation and productivity in tropical ecosystems. Journal of Applied Ecology, 9(3), 747-766. http://dx.doi.org/10.2307/2401901

Moya, I., Daumard, F., Moise, N., Ounis, A., Goulas, Y. 2006. First airborne multiwavelength passive chlorophyll fluorescence measurements over La Mancha (Spain) fields. Paper presented at the $2^{\text {nd }}$ International Symposium on Recent Advances in Quantitative Remote Sensing: RAQRS'II, 25-29 $9^{\text {th }}$ September 2006, Torrent (Valencia)-Spain.

Papageorgiou, G., \& Govindjee (eds). 2004. Chlorophyll a fluorescence. A signature of photosynthesis. Dordrecht, The Netherlands: Springer.

Rossini, M., Meroni, M., Migliavacca, M., Manca, G., Cogliati, S., Busetto, L., Picchi, V., Cescatti, A., Seufert, G., Colombo, R. 2010. High resolution field spectroscopy measurements for estimating gross ecosystem production in a rice field. Agricultural and Forest Meteorology, 150(9) 1283-1296. http:// dx.doi.org/10.1016/j.agrformet.2010.05.011

Schreiber, U., Bilger, W., Klughammer, C., Neubauer, C. 1988. Application of the PAM fluorimeter in stress detection. In H.K. Lichtenthaler (Ed.), Applications of Chlorophyll Fluorescence (pp. 151155). Netherlands: Kluwer Academic Publishers.

Schreiber, U., Schliwa, U. 1987. A solid-state, portable instrument for measurement of chlorophyll luminescence induction in plants. Photosynthesis Research, 11(2), 173-182. http://dx.doi.org/10.1007/ BF00018275 